\title{
Lateral talonavicular dislocation after low-energy trauma
}

\author{
Willem-Maarten Bosman, ${ }^{1}$ Frederik J Prakken, ${ }^{1}$ Bart G Pijls, ${ }^{2}$ Ewan D Ritchie ${ }^{1}$
}

${ }^{1}$ Department of Surgery, Rijnland Ziekenhuis, Leiderdorp, The Netherlands 2Department of Orthopaedics, Leiden University Medical Centre, Leiden,

The Netherlands

\section{Correspondence to} Dr Ewan D Ritchie, e.ritchie@rijnland.n
To cite: Bosman WM, Prakken FJ, Pijls BG, et al. BMJ Case Rep Published online: [please include Day Month Year] doi:10.1136/ bcr-2013-200692

\section{DESCRIPTION}

A 69-year-old woman presented to the emergency department with a painful left foot after a fall from

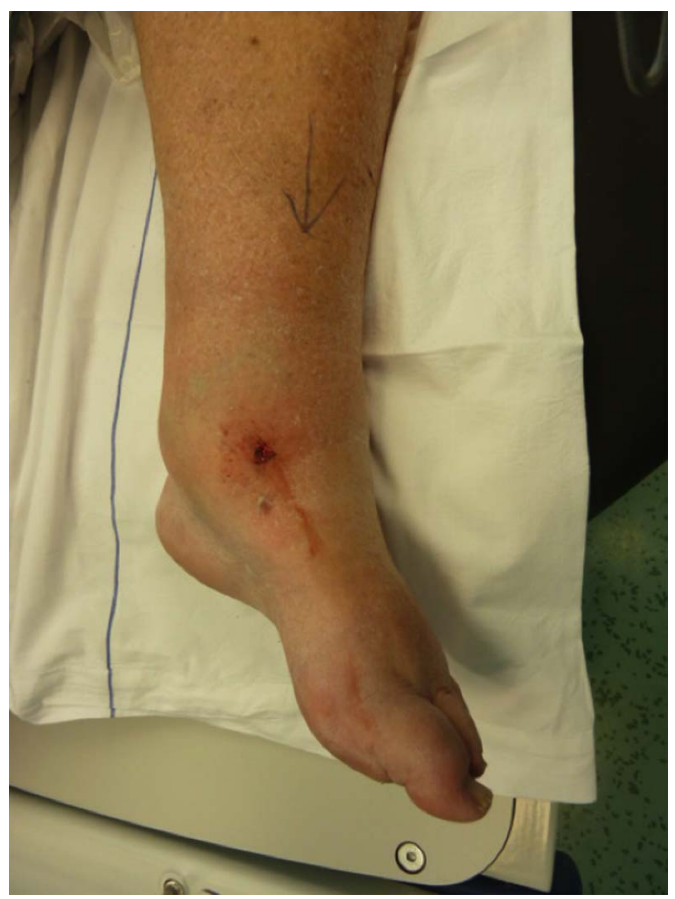

Figure 1 The forefoot is displaced lateral of the talus. Note the disruption of the skin where the talus head presses on the skin. a motorised wheelchair in an attempt to avoid a collision with a cyclist. Medical history included adipositas (body mass index (BMI) 36), diabetes mellitus, polymyalgia rheumatica, angina pectoris, lumbar stenosis L3-L4, total hip prosthesis right and left and total knee prosthesis left. After the fall, she was unable to bear weight. The physical examination was suggestive of lateral dislocation of the foot (figure 1). Pulsations and sensibility appeared intact. The radiographs of the foot/ankle showed a luxation in the talonavicular joint ('Chopart's joint'), whereby the foot was displaced laterally (figure 2). As there was no immediate neurovascular threat, a CT scan was acquired before reposition (figure 3), on which concomitant fractures that may require operative treatment were ruled out.

In the operation theatre, the patient was sedated, to relieve pain and ensure complete relaxation and positioned in supine position. The knee was flexed to diminish tension on the gastrocnemic muscle. The lateral talonavicular luxation was reduced with longitudinal traction on the foot while applying lateral pressure on the talus. Postreduction radiographs confirmed adequate closed reduction, and because the reduction remained stable during stress examinations, no operative fixation was required and a posterior splint was applied.

The postreduction CT scan showed a successful reduction of the talonavicular joint, some small

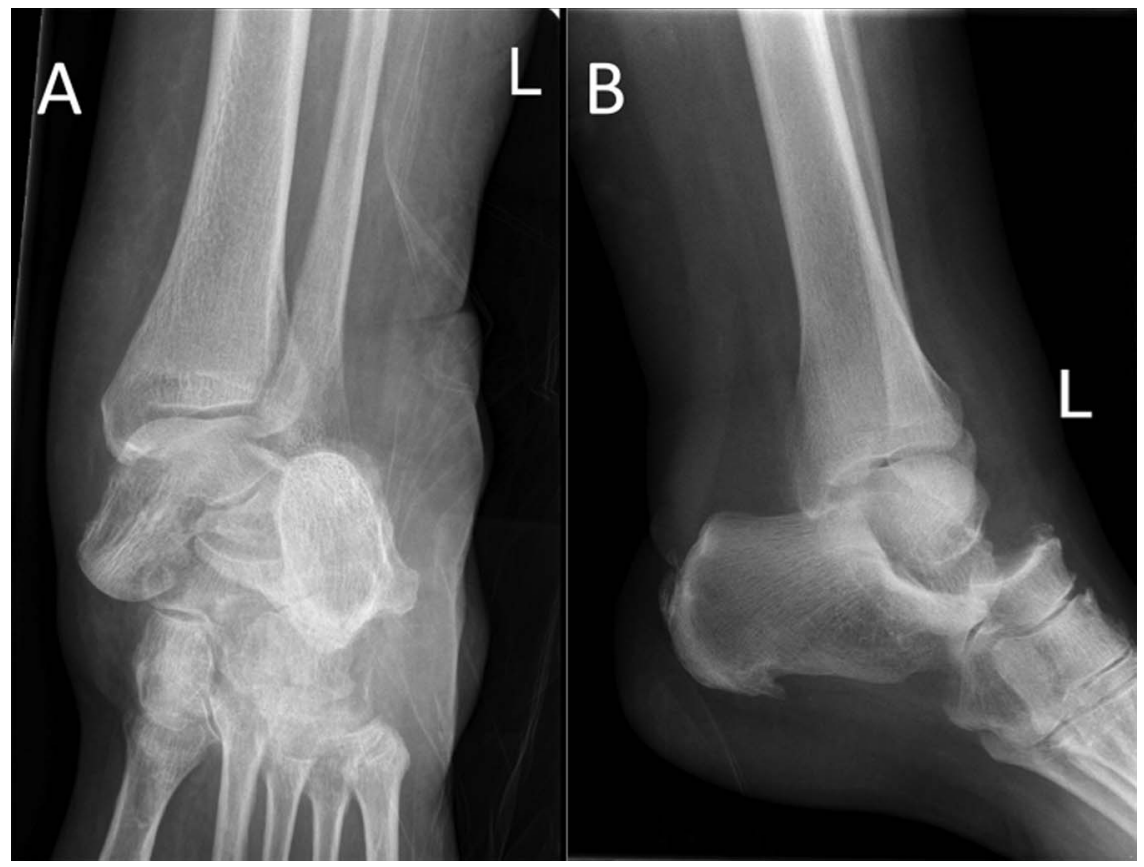

Figure 2 Anteroposterior view (A) and lateral view (B) on conventional X-ray showing clear dislocation of the forefoot compared to the head of the talus. 


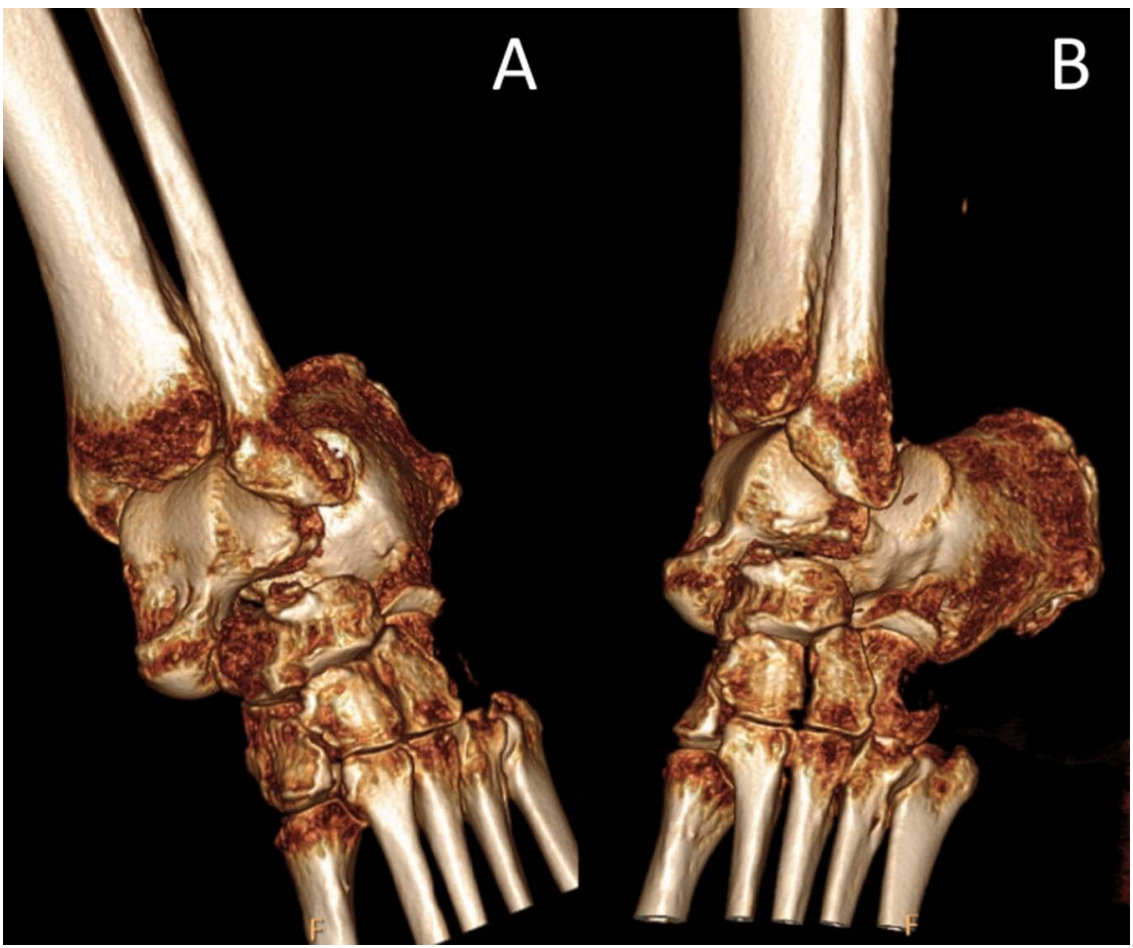

Figure 3 CT reconstruction of the talonavicular dislocation, anteroposterior view (A) and lateral view (B) showing clear dislocation of the forefoot compared to the head of the talus.

avulsion fractures of the medial side of navicular bone, a small avulsion fracture on the lateral side of the cuboid and a small plantar avulsion fracture of the lateral cuneiform. The patient was treated with a non-weight-bearing cast for 6 weeks, followed by a weight-bearing cast for 2 weeks. Follow-up radiographs at 3 and 6 weeks showed no reluxation.

Talonavicular dislocations (or 'Chopart luxations') are very rare injuries. ${ }^{1-3}$ Incidence is estimated at 3.6/100.000/year ${ }^{2}$ and compromise $1-2 \%$ of all luxations. ${ }^{3}$ Up to $80 \%$ of the talonavicular dislocations are medial and just $17 \%$ are lateral (similar to the current case). ${ }^{3}$ The lateral dislocations often occur after a highenergy trauma, such as motor vehicle accidents or fall from a height. ${ }^{1-3}$ Lateral dislocations after a low-energy trauma as in the current case, are rare. The trauma mechanism for a lateral dislocation is often a 'swivel' movement in which the forefoot is hyperabducted, leading to ligamentous rupture and/or avulsion fractures, while the calcaneocuboid joint and the interosseous talocalcaneal ligament remain intact. ${ }^{13}$ The combination of adipositas (BMI 36) and prolonged inactivity may have attributed to lateral talonavicular dislocation after a low-energy trauma in the presented case.

Treatment consists of prompt reduction (technique described above) while the patient is sedated and cast immobilised after reduction. ${ }^{1-3}$ Percutaneous fixation with K-wires may be considered in case of persistent instability. ${ }^{1} 2$

In some cases, closed reduction may be obstructed by interposing structures (ie, flexor digitorum longus tendons, extensor digitorum brevis muscle, dorsal pedis artery and fibular nerve) or by concurrent fractures. ${ }^{3}$ This may necessitate open surgery, removing the interposing structure with reduction of the talonavicular joint and if necessary fixation of concurrent fractures.

Short-term complications consist of necrosis of the skin (due to pressure of the talus head on the skin) and reluxation of the joint, while long-term complications consist of reduction of subtalar joint motion, avascular necrosis of the talus and chronic, progressive, post-traumatic arthritis. ${ }^{3}$

\section{Learning points}

- A talonavicular dislocation is a rare luxation of the foot often after a high-velocity trauma.

- Up to $80 \%$ of the talonavicular dislocation is medial, $17 \%$ lateral.

- The lateral dislocation can be reduced under sedation with flexion in the knee, longitudinal traction on the foot and lateral pressure on the talus.

- If closed reduction fails, that is, due to interposition, open reduction may be necessary.

Contributors WMB, FJP, BGP and EDR were involved in the treatment of the patient. WMB and BGP conducted the literature search. WMB, FJP and BGP were involved in the drafting of the manuscript. FJP, BGP and EDR performed the article review.

Competing interests None.

Patient consent Obtained.

Provenance and peer review Not commissioned, externally peer reviewed.

\section{REFERENCES}

1 Gaddy B, Perry CR. Chopart dislocation: a case report. J Orthop Trauma 1993;7:388-90.

2 van Dorp KB, de Vries MR, van der Elst $M$, et al. Chopart joint injury: a study of outcome and morbidity. J Foot Ankle Surg 2010;49:541-5, Elsevier Ltd.

3 Tucker DJ, Burian G, Boylan JP. Lateral subtalar dislocation: review of the literature and case presentation. J Foot Ankle Surg 1998;37:239-47. 
Copyright 2013 BMJ Publishing Group. All rights reserved. For permission to reuse any of this content visit http://group.bmj.com/group/rights-licensing/permissions.

BMJ Case Report Fellows may re-use this article for personal use and teaching without any further permission.

Become a Fellow of BMJ Case Reports today and you can:

- Submit as many cases as you like

- Enjoy fast sympathetic peer review and rapid publication of accepted articles

- Access all the published articles

- Re-use any of the published material for personal use and teaching without further permission

For information on Institutional Fellowships contact consortiasales@bmjgroup.com

Visit casereports.bmj.com for more articles like this and to become a Fellow 